\title{
Electronic Markets on platform competition
}

\section{Rainer Alt ${ }^{1} \cdot$ Hans-Dieter Zimmermann ${ }^{2}$}

Published online: 15 June 2019

(C) Institute of Applied Informatics at University of Leipzig 2019

\section{Dear readers,}

The present issue of Electronic Markets combines two special issues and one general research article. They provide an opportunity to reflect on the competition of electronic (or digital) platforms that have already left strong marks in the global economy and transformations of many businesses as well as industry sectors are under way. In the latest ranking of the largest companies worldwide by market value (Murphy et al. 2019), seven entries from the top ten companies are held by providers of electronic platforms (Apple, Microsoft, Amazon, Alphabet, Facebook, Alibaba, Tencent). While Microsoft has been populating this ranking for almost two decades, Apple has appeared in 2010, Google in 2013 and Amazon as well as Facebook in 2016. Over the years, all of these companies remained in the ranking while other IT companies, such as Intel or IBM, have dropped out after some appearances again. It was only in 2017 that the so far dominating US companies saw the first competitors from Asia. One of them, Tencent, is a Chinese technology conglomerate founded in 1998. Among others, it operates the communication and payment service WeChat, which features more than one billion users. The other, Alibaba, also originates from China and owns Taobao, which was founded in 2003 and today is recognized as the largest e-commerce website worldwide with over 600 million active monthly users. Remarkably, no European businesses are to be found in the top ten rankings. Although companies, such as Experian from Ireland and Otto Group from Germany, appeared among the top twenty global internet companies by

Rainer Alt

rainer.alt@uni-leipzig.de

Hans-Dieter Zimmermann

hansdieter.zimmermann@fhsg.ch

1 Information Systems Institute, Leipzig University, Grimmaische Str. 12, 04109 Leipzig, Germany

2 FHS St. Gallen, University of Applied Sciences, 9001 St. Gallen, Switzerland market value in 2012, the competition is mainly between the US and China (Simon 2018).

\section{Characteristics of electronic platforms}

This is not surprising as China is not only a large and fastmoving domestic market, but Chinese companies are seizing markets abroad in the US as well as in Europe. Like some of their US competitors they are rather young - Microsoft was founded in 1975, Amazon in 1994, Google in 1998 and Facebook in 2004 - and now compete on eye level with the Western giants. For example, in terms of gross merchandise volume (GMV) Alibaba outperformed Amazon in 2018 by more than 200\% (figures from Alibaba (2018) and Bezos (2019) even show 277\%). On the one hand, this impressively shows that electronic platforms have become key drivers of economic growth with some of the largest and most valuable companies worldwide being platform providers. On the other hand, the transformation occurred almost within a single decade and illustrates the speed of a process, which has influenced the competitive landscape in many industries (e.g. Parker et al. 2016). Although national borders still impose barriers in terms of market access, regulation and language, electronic platforms have the potential and the intention to compete on a global basis. This may be rooted in the fundamental differences between pipeline and platform businesses (van Alstyne et al. 2016, see Table 1). The former describe the traditional supply chain model, whereas a company (e.g. an automotive manufacturer or a bank) strikes long-term deals with suppliers as well as dealers and seeks efficient supply chain processes. The goal is to gain competitive advantage via products, which are difficult to imitate and which convince consumers due to their superior product features.

As shown in Fig. 1, platform businesses follow a different logic. The value of platform owners, such as AirBnB, Amazon, Booking.com, Ebay, Facebook, Lyft or Uber (and many more, see Parker et al. 2016) emerges not from orchestrating the supply chain of specific products, but from 
Table 1 Economics in pipeline and platform businesses

\begin{tabular}{lll}
\hline & Supply chain / pipeline businesses & Multi-sided platform businesses \\
\hline Value & Pipeline products have features & Platforms have communities \\
Focus & Growing transactions (sales volume) & Growing interactions (views, downloads) \\
Access & Erecting barriers & Eliminating barriers \\
Metrics & Optimizing processes & Achieving liquidity \\
\hline
\end{tabular}

establishing and nurturing communities. By nature, platform businesses are intermediaries, which becomes apparent in the types of actors that are involved in platforms (van Alstyne et al. 2016, p. 4; Gawer and Cusumano 2014): providers create products and services that are offered on the platform to consumers. The platform itself comprises the platform owner, who leads the development of the platform and who defines the rules of the game on the platform. In addition, platforms offer a variety of services. This includes platform technologies, which provide access to the platform (e.g. the Booking.com platform may be accessed via Android, iOS and the Web) and other services, which support the coordination on the platform (e.g. catalogs, payment, logistics). Depending on the platform leader's strategy, platform services may be provided by the leader or by external partners. This inclusion of external partners has led many platforms to become ecosystems since they "provide the foundation upon which outside firms (organized as a "business ecosystem") can develop their own complementary products, technologies, or services" (Gawer and Cusumano 2014, p. 418). Although the relationship between platforms and ecosystems often remains unspecific (de Reuver et al. 2018, p. 126), the provision of complementary offerings on a platform is a key element of ecosystems. These complementary resources may be coupled rather loosely (e.g. be listed in a common catalog/app store) or even feature functionalities that are interoperable with other offerings in the ecosystem (e.g. closer alignment and interoperability like within a service-oriented architecture).

Although electronic platforms have enjoyed much attention in recent years, a large body of knowledge from past research in the field of electronic markets (see e.g. Alt and Klein 2011) contributes to the understanding of platform dynamics. Electronic platforms may be revolutionary regarding

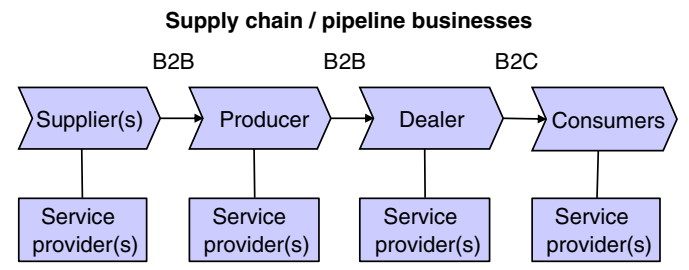

\section{Legend:}

B2B: Business-to-business

B2C: Business-to-customer/consumer

C2C: Consumer-to-consumer their impact on many industries, however, they are evolutionary when compared to electronic markets that emerged more than 30 years ago. In comparison with the electronic markets' term, every electronic market in the narrow interpretation (Alt and Zimmermann 2014, p. 162) may be conceived as an electronic platform, but not every electronic platform as an electronic market. Electronic markets focus on the coordination of multiple actors. On the one hand, they provide and on the other they consume physical or immaterial resources. By providing a location where supply and demand for these resources meet, they have important advantages compared to sequential supply chain topologies. For example, each supply chain actor typically has relationships with several service providers (e.g. banks, distributors, freight forwarders, suppliers) and replacing bilateral relationships with a platform significantly reduces the dependencies in a supply chain (Tröger and Alt 2017). An electronic market typically comprises two groups ("sides") that want to interact with each other, while supply chains are one-sided in nature and should not be referred to as platforms in a narrower sense (Tiwana 2014, p. 9). Bringing together these two groups not only reduces the complexity of interfaces and increases the transparency over distributed activities but also allows more dynamic allocation processes. For example, "multi-sided" markets may dissolve the strict sequential supply chain role model when consumers act as providers of resources (e.g. rooms, cars, energy, opinions) on the platform as well (e.g. Eisenmann et al. 2006, Evans 2011). This leads to the first two characteristics of electronic platforms:

- First, electronic platforms offer nodes linking multiple actors on each side, i.e. more than one provider and more than one consumer. As indicated by the dotted lines in Fig.

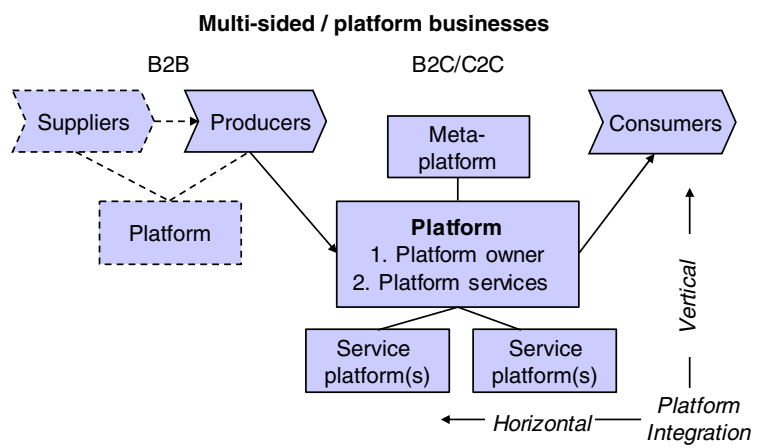

Fig. 1 Specifics of platform businesses 
1 , there is room for multiple of such nodes to establish themselves at various stages of a value creation process. Platforms are not necessarily replacing supply chain designs, but may position themselves between the tiers of a supply chains and key (so-called focal) actors may also decide to establish platforms that link all participants of their supply chain. In this way, many platforms emerged from large actors (e.g. automotive, apparel or food producers, see Tröger and Alt 2017). Although technological platforms (e.g. operating systems) may be used broadly, it seems unlikely that a single electronic platform dominates all activities within a value chain. In particular, the differentiation between professional (B2B) and private participants $(\mathrm{B} 2 \mathrm{C}, \mathrm{C} 2 \mathrm{C})$ has given rise to different platforms. The same may be observed for different industries where platforms vary depending on the underlying resources, for example, media, finance, cars, pharmaceuticals or groceries. Thus, due to specialization effects multiple platforms might position themselves along a value chain.

- Second, electronic platforms offer different services via their infrastructure. While the platform owner might provide services for accessing and governing the platform (e.g. registration, user ratings, compliance monitoring), a variety of further platform services is possible, which may also be offered by external providers. In general, coordination services (e.g. catalogs, comparison and auction sites) directly affect transactions whereas supporting services (e.g. payment, logistics, trust) may be used for many coordination services on a platform as well as for different platforms. Figure 1 also shows that supporting services such as Paypal may be seen as platforms on their own. In addition, platforms may be complemented by metaplatforms that provide an overview on many platforms such as Trivago over other reservation sites, such as Booking.com, Hotels.com or Expedia. This means that depending on their functionality (or service offering) multiple platforms are possible that may complement each other and may be integrated along a vertical and a horizontal dimension towards larger platform ecosystems (Tiwana 2014).

\section{Platform competition}

Following the two characteristics (nodes, services), platforms may differ in terms of the participants who are using the platform as well as regarding the platform owner and the various services offered. This yields opportunities for platforms to emerge and many electronic markets have done so in the past (see examples in (Alt and Klein 2011, p. 45) and (Evans 2011, p. 12). For example, new entrants, such as startup-businesses, will identify the opportunities for intermediation (e.g. market intransparencies and fragmentation, see Giaglis et al. 2002) with many of the large platform businesses (e.g. Alphabet, Amazon, Facebook, Uber) being prominent examples. At the same time, incumbent (pipeline) businesses might be successful in developing platform businesses. For example, automotive manufacturers have launched mobility platforms for ridesharing (e.g. share now by Daimler and BMW) as have automotive suppliers (e.g. supplyon by Bosch, Continental, Schaeffler and ZF). In a similar vein, banks pursue open banking strategies that foresees platforms where many banks contribute services that complement each other (Zachariadis and Ozcan 2017). Despite the many opportunities for electronic platforms to emerge, the third characteristic points in the direction of the traffic on the respective platforms.

Known as network externalities, the amount of interactions on a platform strongly influence the attractiveness of this platform. Since platforms are infrastructure goods, communities where many counterparts exist for interactions and/or transactions, will be more beneficial to their users and attract further users. In the case of positive network externalities these platforms tend to grow fast and by reaching a dominant position in their respective markets they may lead to monopolistic market structures. With negative network externalities, the opposite development occurs and attaining a critical mass of users as well as interactions will be less and less likely. Negative effects are even possible once a critical mass has already been accomplished. This may be observed with social networking platforms, such as StudiVZ in Germany or mySpace in the US, where users left to competitors. In fact, critical mass is a rather subjective construct, which is influenced by individual expectations and observations. Successful platforms such as Amazon or Alibaba illustrate that platforms require constant enhancements and nurturing. Both platforms now provide comprehensive services around transactions from inbound, inhouse, and outbound logistics to payment solutions for customers as well as to value added services such as entertainment features that complement their core business (i.e. online shopping). Integrating additional features tends to increase the value add of an ecosystem and serves as a differentiating feature. In addition, there is not a single network effect. Due to the combination of many services as well as platforms, multiple direct and indirect network effects may coincide (Alt and Klein 1998). This may refer to interfacing services (e.g. platforms such as Android or iOS), to payment or logistics services (e.g. platforms such as PayPal or RIO) or coordination services (e.g. auctions such as ebay). It may be assumed that platforms have competitive advantages if multiple positive network externalities accrue and if strong horizontal as well as vertical platform integration occurs. Overall, the competitive forces indicate that competition may be expected to increase (see also Forbes 2014):

- Rivalry: Critical mass effects imply that only a limited number of platforms within a certain segment will be 
economically viable. Thus, existing platform providers put large efforts into enhancing their platforms with additional functionalities and services. This is reflected in the strong R\&D investments of global internet companies (see Simon 2018, p. 604).

- Substitutes: Driven by technological progress, new coordination concepts may threaten existing platforms, which follow a centralized topology. An example are the recent decentralized Blockchain-based platforms, which operate without centralized intermediaries and promise to streamline activities in various tiers of a supply chain.

- Suppliers: Providers will offer their services on platforms that have reached or are expected to reach a critical mass. This is driven by platform-specific investments due to proprietary application environments and possible integrations with other platform services. For example, many providers refrained from offering their services on the Microsoft Marketplace.

- Customers: Similar to suppliers, the consumers on a platform will also be motivated to use platforms that have reached a critical mass of users and interactions (so-called liquid markets). Although consumers might have presences on more than one platform due to low platformspecific investments, the number of actively used platforms for the same purpose will be limited.

- New entrants: Companies from previously separate industries might decide to establish platform businesses themselves. For example, open banking strategies foresee that banks develop app stores and allow external service providers - sometimes even competitors - to offer services on these platforms. An example is Fusionfabric.Cloud from Finastra. In a similar way, platforms might enhance their services and enter other industries. This is the case when Amazon, Google, Facebook or Instagram offer financial services to their users.

While the large (existing and future) potential for platforms drives many players to establish platforms, the rules of the game defined by network externalities will limit the number of liquid and sustainable platforms. In consequence, not every business will be able to act as platform owner and orchestrator of a liquid platform. Many providers will aim to position their services in multiple platforms. Platform competition also means that economic and political rationale have to be considered. From an economic perspective, the presence of network externalities favors global platforms and almost inevitably leads to monopolistic inclinations. This causes regulators and politicians to critically observe these developments, especially in Europe and the US. Not for the first time, politicians demand to break up platform giants, which are recognized as monopolies that fail to comply with competition legislation. It was in 1982 that the US regulators destroyed the AT\&T monopoly resulting in the emergence of the so called 'Baby
Bells'. In the airline industry, computerized reservation system (CRS) have been subject to regulatory investigation and interventions several times (see Copeland and McKenney 1988). In Europe, Microsoft as well as Google were foreced to adapt their platform strategies due to regulatory investigations for abuse of their dominant position in the market according to competition law.

\section{Special issue articles}

The political landscape in many of the emerging markets is different to the US and to Europe. In particular, the large Chinese platforms from Alibaba and Tencent already have a large home market and feature a variety of well-integrated services, which serve to increase network externalities. They operate in different economic as well as political environments and Western platforms struggle to enter the Chinese market. For example, Amazon recently decided to exit the Chinese market (Liao 2019). However, as soon as Chinese companies choose to extend their platforms to Europe and the US they will have to comply with the competitive laws in these marketplaces as well. This tends to level the competitive basis with an intensified competition between the Western platforms and those from the emerging markets being likely. Again, network effects are a strong economic driver, which might be balanced by monopolistic and political concerns. Understanding the developments of electronic markets in these emerging markets should be relevant for platform participants worldwide. As shown in Table 2, Electronic Markets has a tradition in publishing research on emerging markets, which dates back to 1997. In total, it comprises four special issues with the fifth being included in the present issue. Titled "Electronic markets in emerging markets", the guest editors Li Da Xu, Sohail Chaudhry and Xiongfei Cao present four research articles, which are introduced in more detail in their preface (Cao et al. 2019). Although all papers investigate different aspects of the large Chinese platforms, the guest editors emphasize that emerging markets are not limited to China, but that Brazil, India or Russia should be observed as well.

In focusing on recommender systems, the second special theme of this issue sheds light on a fourth characteristic of electronic platforms. This conceives electronic platform as valuable data resources for forecasting and demand-oriented strategies following Zysman and Kenney $(2018$, p. 63) whereas "the greatest strategic advantage for platform firms is their algorithms and the data they collect". Again, history suggests, that this is not new. In fact, the large airline CRS already sold anonymized aggregated data from their platforms in the 1980s and showed that all user activities (e.g. searches, transactions, opinions) on an electronic platform may be helpful in determining what should be offered to travel agents and/ or consumers. Besides selling these insights, platform owners 
Table 2 Articles published in Electronic Markets on emerging markets

Issue Topics of special issue or article

26(1)
Sun, Y., Kuang, X., \& Sun, D. (2016). The geographic concentration of China's e-business enterprises: where they gather and why, https://doi.org/10.1007/s12525-015-0201-2 .

Peng, L., \& Lai, L. (2014). A service innovation evaluation framework for tourism e-commerce in China based on BP neural network, https://doi.org/10.1007/s12525-013-0148-0 .

Liu, C., Yao, L.J., Sia, C.L., \& Wei, K.K. (2014). The impact of early XBRL adoption on analysts' forecast accuracy - empirical evidence from China, https://doi.org/10.1007/s12525-013-0132-8 .

Sun, Y., Liu, L., Peng, X., Dong, Y., \& Barnes, S.J. (2014). Understanding Chinese users' continuance intention toward online social networks: an integrative theoretical model, https://doi.org/10.1007/s12525-013-0131-9 .

Guo, X., Sun, Y., Wang, N., Peng, Z., \& Yan, Z. (2013). The dark side of elderly acceptance of preventive mobile health services in China, https://doi.org/10.1007/s12525-012-0112-4 .

Special issue on "E-Commerce Intelligence Development and Research in the Greater China Region"

Shao, B., Shi, L., Xu, B., \& Liu, L. (2012). Factors affecting participation of solvers in crowdsourcing: an empirical study from China, https://doi.org/10.1007/s12525-012-0093-3 .

Liu, Y., \& Sutanto, J. (2012). Buyers' purchasing time and herd behavior on deal-of-the-day group-buying websites, https://doi.org/10.1007/s12525-012-0085-3 .

Yan, J., Guo, Y., \& Schatzberg, L. (2012). Coordination mechanism of IT service supply chain: an economic perspective, https://doi.org/10.1007/s12525-012-0086-2 .

Gao, P. (2008). A framework for analyzing emerging business models: cases of China's media industry, https://doi.org/10.1080/10196780802420729.

Special issue on "Electronic Business in China"

Chen, J., Zhang, C., Yuan, Y., \& Huang, L. (2007). Understanding the emerging C2C electronic market in China: an experience-seeking social marketplace, https://doi.org/10.1080/10196780701292468 .

Lu, Y., Deng, Z., \& Wang, B. (2007). Tourism and travel electronic commerce in China, https://doi.org/10.1080/10196780701295974 .

Kshetri, N. (2007). The adoption of e-business by organizations in China: an institutional perspective, https://doi.org/10.1080/10196780701296022 .

Srivastava, A., \& Thomson, S.B. (2007). E-business law in China: strengths and weaknesses, https://doi.org/10.1080/10196780701296121 .

Brown, D.H., \& He, S. (2007). Patterns of ERP adoption and implementation in China and some implications, https://doi.org/10.1080/10196780701296287.

Xu, S., Zhu, K., \& Gibbs, J. (2004). Global technology, local adoption: a cross-country investigation of internet adoption by companies in the United States and China, https://doi.org/10.1080/1019678042000175261 .

Okazaki, S. (2004). Does culture matter? Identifying cross-national dimensions in Japanese multinationals' product-based websites, https://doi.org/10.1080/1019678042000175306 .

Special issue on "Electronic commerce in Austral-Asia"

Lohse, G.L., \& Wu, D.J. (2001). Eye movement patterns on Chinese yellow pages advertising, https://doi.org/10.1080/101967801300197007 .

Poon, S., \& Chau, P.Y.K. (2001). Octopus: The growing e-payment system in Hong Kong, https://doi.org/10.1080/101967801300197016 .

Damsgaard, J., \& Farhoomand, A. (1999). Electronic commerce in Hong Kong special administrative region of the People's Republic of China, https://doi.org/10.1080/101967899359274 .

Liu, Z. (1997). China's information super highway: its goal, architecture and problems, http://www.electronicmarkets.org/archive/issues/volume-7/volume-7-issue-4/.

Special issue on "Electronic commerce in Asia" (http://www.electronicmarkets.org/archive/issues/volume-7/volume-7-issue-2/)

Westland, J.C., Kwok, M., Shu, J., Kwok, T., \& Ho, H. (1997). Electronic cash in Hong Kong.

Kim, E., \& Hong, P. (1997). The government's role in diffusion of EC in Korea.

Yen, B.P.C., \& Su, C.T. (1997). Information technology infrastructure for textile and apparel industry in Hong Kong.

Kim, J. (1997). Toward the construction of customer interfaces for cyber shopping malls - HCI research for electronic commerce.

Bhatnagar, S. (1997). Electronic commerce in India: the untapped potential.

Westland, J.C., \& Ming, S.S. (1997). Automation of China's securities markets.

Asuncion, R.M. (1997). Potentials of electronic markets in the Philippines. may use the data to make their platform more attractive to users and to foster network effects. Both observations are underpinning the saying whereas data is the "oil" of platform businesses. Recommender or recommendation systems use this raw data as input for analytic purposes and derive insights for preferences, purchasing patterns and customer demand in 
general. They often rely on algorithms from artificial intelligence and it may be assumed that large platform providers invest heavily to sophisticate their systems. Recommender systems have received repeated attention in Electronic Markets in the past with many contributions focusing on personalized offerings and pricing (see Table 3). Some recent research results are included in the second special theme of the present issue. It was organized by Yin Zhang, Haider Abbas, and Yi Sun and is titled "Smart e-commerce integration with recommender systems". The guest editors introduce all three contributions together with a brief overview on the functionalities of recommender systems in their preface (Zhang et al. 2019). We would like to thank both guest editor teams for their valuable work in organizing these two special issues as well as all authors and reviewers who were involved.

Finally, the two special issues are complemented by a general research article titled "Beyond markets, hierarchies, and hybrids: an institutional perspective on IT-enabled two-sided markets", authored by Kai Reimers, Xunhua Guo, and Mingzhi Li. This contribution sheds light on two-sided markets through the lens of institutional economics rather than a technical perspective. It defines two-sided platforms as "arrangement[s] where an intermediary brings together two distinct 'user groups' who provide each other with network benefits" (Reimers et al. 2019). The authors develop a novel framework to classify and characterize two-sided markets based on transaction cost theory by extending this conceptual framework. They provide an important contribution to the scholarly debate about the role of information technology in transformation processes by providing a conceptual framework for the emergence of two-sided markets. The three types of electronic platforms serve to advance the understanding of platform businesses as well. Electronic Markets will continue to explore the four introduced aspects of electronic platforms (nodes, services, network externalities, data resources) in future special issues. Some of them are already scheduled, such as a special issue on multi-sided platforms, a special issue on recommendation systems, a special issue on hybrid intelligence in business networks as well as the special issue on the evolution and the perspectives on electronic markets - the latter being planned for the 30 years jubilee issue of Electronic Markets.

\section{Electronic Markets awards 2018}

Finally, each volume's second issue is also the opportunity for announcing the awards of Electronic Markets. The first award category presents the outstanding reviewers of the previous year. It honors a key resource for an academic journal since reviewers determine and secure the quality in the review process. The selection process for the outstanding reviewers at Electronic Markets consists of two stages. First, it is based on quantitative data from Electronic Markets' reviewing system, such as the number of agreed and submitted reviews within the agreed time schedule as well as "in-time" completion of the reviews. Second, the review rating by Electronic Markets' editors was taken into account, and, third and most decisively, the content-related quality of the reviews was evaluated by the editorial team. This led to the selection of the folllowing four outstanding reviewers for the year 2018:

- Harry Bouwman, University of Technology Delft, The Netherlands

- Mark de Reuver, Delft University of Technology, The Netherlands

- Katharina Ebner, FernUni Hagen, Germany

- Mathias Klier, Ulm University, Germany

The second awards category refers to Electronic Markets' papers of the year 2018. To identify them, the most cited and

Table 3 Articles published in Electronic Markets on recommendation systems

Issue Topics of special issue or article

20/2 Backhaus, K., Becker, J., Beverungen, D., Frohs, M., Müller, O., Weddeling, M., Knackstedt, R., \& Steiner, M. (2010). Enabling individualized recommendations and dynamic pricing of value-added services through willingness-to-pay data, https://ink.springer.com/article/10. 1007/s12525-010-0032-0

24/3 Pappas, I.O., Kourouthanassis, P.E., Giannakos, M.N., \& Chrissikopoulos, V. (2014). Shiny happy people buying: the role of emotions on personalized e-shopping, https://link.springer.com/article/10.1007/s12525-014-0153-y.

25/2 Heimbach, I., Gottschlich, J., \& Hinz, O. (2015). The value of user's Facebook profile data for product recommendation generation, https://ink. springer.com/article/10.1007/s12525-015-0187-9.

26/1 Matt, C., \& Hess, T. (2018). Product fit uncertainty and its effects on vendor choice: an experimental study, https:/link.springer.com/article/10. 1007/s12525-015-0199-5.

26/4 Köhler, S., Wöhner, T., \& Peters, R. (2016). The impact of consumer preferences on the accuracy of collaborative filtering recommender systems, https://link.springer.com/article/10.1007/s12525-016-0232-3.

27/3 Buettner, R. (2017). Predicting user behavior in electronic markets based on personality-mining in large online social networks, https://ink. springer.com/article/10.1007/s12525-016-0228-z. 
most downloaded papers published in Electronic Markets in 2017 were determined. The senior and the associate editors then had the opportunity to vote on the top five ranked papers, which led to the two winning papers. These are:

- Ricardo Buettner (2017). Predicting user behavior in electronic markets based on personality-mining in large online social networks. Electronic Markets, 27 (3), pp. 247-265.

- Kai Huotari and Juho Hamari (2017). A definition for gamification: anchoring gamification in the service marketing literature. Electronic Markets, 27 (1), pp. 21-31.

The Electronic Markets team wishes to congratulate all six colleagues for their achievement!

\section{References}

Alibaba. (2018). Alibaba Group announces March quarter 2018 results and full fiscal year 2018 results. Alibaba Group, May 4. https:// www.alibabagroup.com/en/news/press pdf/p180504.pdf. Accessed 31 May 2019.

Alt, R., \& Klein, S. (1998). Learning from failure: The myths and magic of electronic transportation markets. Proceedings $31^{\text {st }}$ Hawaii International Conference on System Sciences, IEEE. https://doi. ieeecomputersociety.org/10.1109/HICSS.1998.655265 .

Alt, R., \& Klein, S. (2011). Twenty years of electronic markets research looking backwards towards the future. Electronic Markets, 21(1), 41-51. https://doi.org/10.1007/s12525-011-0057-z .

Alt, R., \& Zimmermann, H.-D. (2014). Editorial 24/3: Electronic Markets and general research. Electronic Markets, 24(3), 161-164. https:// doi.org/10.1007/s12525-014-0163-9 .

Bezos, J. P. (2019). 2018 Letter to Shareholders. Amazon Inc., April, 11. https://blog.aboutamazon.com/company-news/2018-letter-toshareholders. Accessed 31 May 2019.

Buettner, R. (2017). Predicting user behavior in electronic markets based on personality-mining in large online social networks. Electronic Markets, 27(3), 247-265.

Cao, X., Chaudhry, S., \& Da Xu, L. (2019). Electronic markets in emerging markets. Electronic Markets, 29(2). https://doi.org/10.1007/ s12525-019-00343-0 .

Copeland, D. G., \& McKenney, J. L. (1988). Airline reservations systems: Lessons from history. MIS Quarterly, 12(3), 353-370.

de Reuver, M., Sørensen, C., \& Basole, R. C. (2018). The digital platform: A research agenda. Journal of Information Technology, 33(2), 124-135.

Eisenmann, T., Parker, G., \& van Alstyne, M. W. (2006). Strategies for two-sided markets. Harvard Business Review, 84(10), 92-101.

Evans, D.S. (2011). Platform economics: Essays on multi-sided businesses, Competition Policy International. http://ssrn.com/abstract= 1974020, Accessed May 19, 2019.
Gawer, A., \& Cusumano, M. A. (2014). Industry platforms and ecosystem innovation. Journal of Product Innovation Management, 31(3), 417-433. https://doi.org/10.1111/jpim.12105 .

Giaglis, G. M., Klein, S., \& O'Keefe, R. M. (2002). The role of intermediaries in electronic marketplaces: Developing a contingency model. Information Systems Journal, 12(3), 231-246. https://doi.org/10. 1046/j.1365-2575.2002.00123.x .

Huotari, K., \& Hamari, J. (2017). A definition for gamification: anchoring gamification in the service marketing literature. Electronic Markets, 27(1), 21-31.

Liao, S. (2019). Amazon admits defeat against Chinese e-commerce rivals like Alibaba and JD.com. The Verge, April 18. https://www. theverge.com/2019/4/18/18485578/amazon-china-marketplacealibaba-jd-e-commerce-compete. Accessed 18 May 2019.

Murphy, A., Ponciano, J., Hansen, S., \& Touryalai, H. (2019). Global 2000 - The world's largest public companies. Forbes, May 15. https://www.forbes.com/global2000, retrieved on May 18, 2019.

Parker, G.G., van Alstyne, M.W., \& Choudary, S. P, (2016). Platform revolution: How networked markets are transforming the economy and how to make them work for you. Norton, New York/London.

Reimers, K., Guo, X., \& Li, M. (2019). Beyond markets, hierarchies, and hybrids: An institutional perspective on IT-enabled two-sided markets. Electronic Markets, 29(2). https://doi.org/10.1007/s12525018-0319-0 .

Simon, J. P. (2018). Global internet market capitalisation leaders: Where is the EU? Digital Policy, Regulation and Governance, 20(6), 600 608. https://doi.org/10.1108/DPRG-09-2018-062 .

Tiwana, A. (2014). Platform ecosystems: aligning architecture, governance, and strategy. Burlington: Morgan Kaufmann, Amsterdam etc.

Tröger, R., \& Alt, R. (2017). Design options for supply chain visibility services: Learnings from three EPCIS implementations. Electronic Markets, 27(3), 141-156. https://doi.org/10.1007/s12525-0160231-4 .

Van Alstyne, M. W., Parker, G. G., \& Choudary, S. P. (2016). Pipelines, platforms, and the new rules of strategy. Harvard Business Review, 94(4), 54-62.

Zachariadis, M., \& Ozcan, P. (2017). The API economy and digital transformation in financial services: The case of open banking. Swift Institute Working Paper No. 2016-001. https://ssrn.com/abstract= 2975199, retrieved on May 18, 2019.

Zhang, Y., Abbas, H., \& Sun, Y. (2019). Smart e-commerce integration with recommender systems. Electronic Markets, 29(2). https://doi. org/10.1007/s12525-019-00346-x .

Zysman, J., \& Kenney, M. (2018). The next phase in the digital revolution: Intelligent tools, platforms, growth, employment. Communications of the ACM, 81(2), 54-63. https://doi.org/10. $1145 / 3173550$.

Publisher's note Springer Nature remains neutral with regard to jurisdictional claims in published maps and institutional affiliations. 